\title{
The new European Respiratory Journal: alive and kicking
}

\author{
M. Decramer (Chief Editor)
}

As of January 1 2001, the start of the new millennium, the new European Respiratory Journal (ERJ) was born, because this is the first year that we publish the ERJ in full ownership and with full responsibility for the production process. We are confident that because of the year long preparation and the dedicated staff in Sheffield this event will pass by unnoticed by the members of the Society and the subscribers to the Journal. We are convinced that the Journal you will receive this year will be better than the Journal produced during the past years. This is primarily the result of the hard work of both our Editorial Board and our staff in Sheffield. The improvement of our product is related to several aspects.

The Journal has been distributed on-line since May 2000. It is easily accessible through the European Respiratory Society (ERS) website and presently access is free. From June 2001, access will be limited to members only. We are planning to drastically increase the functionality of this on-line Journal in the next few years. This will be done through the installation of services such as automatic e-mail alert, hyperlinks and reference cross-links. We will attempt to follow the fast evolution of publishing on-line and we will work with the best partners in the field. These developments will improve access to the Journal and help the members of the Society to make even better use of their Journal.

The performance indicators of manuscript handling have improved considerably during the last year. This is largely due to a simplified manuscript handling scheme. Figure 1 shows the evolution of the number of manuscripts submitted to the ERJ during the past years. As can be seen this number increased substantially during the last decade. During the last three years, however, a plateau was reached at approximately 1,100 manuscripts per year. A small decrease was noticed in the last two years. We have improved the speed of handling manuscripts substantially as can be appreciated from figure 2. During the last year the average time to verdict i.e. the time from first submission to first verdict averaged 45 days, which is a substantial improvement over the previous years where it averaged 60 days. The time to publication has been reduced to 4 months or less. These improvements were necessary to

Respiratory Division, University Hospitals, Katholieke Universiteit Leuven, Belgium.

Correspondence: M. Decramer, Respiratory Division, University Hospital Gasthuisberg, Herestraat 49, B-3000 Leuven, Belgium. Fax: 3216346803 bring the news to you in a timely fashion. We are determined to substantially reduce the time to publication further still.

As of January 2001, we started with a fully automated on-line submission, reviewing and manuscript handling system. This system will allow for the elimination of all postal delays, which presently exist, when mailing manuscripts between members of the editorial board. We anticipate that this will lead to a further substantial reduction in the verdict time. We will aim at guaranteeing a verdict within 40 days or less. Besides faster manuscript handling, the on-line submission system will have other clear advantages. The submission process will become considerably simpler as the printing and copying of manuscripts and glossy prints of figures etc. will no longer be necessary. In addition, the authors will be able to follow the whole review process of their paper on-line, thus avoiding anxiety and poor communication. Obviously, the anonymity of the reviewers will be ensured. Moreover, this on-line submission system will help us to perform the review process better as it will allow us to have a fully automated reviewer database, in which the data on the reviewers will be stored. This will help us to better identify reviewers who regularly provide us with excellent and timely reviews. Consequently, we anticipate taking better decisions than in the past. Finally, this system will pave the way for further improvement of the Journal production process as it will allow for the move to on-line technical editing, type setting and other on-line applications. These will probably allow us to produce a better quality journal at a lower cost. They will be fully implemented at the end of 2001 . Please submit your manuscripts electronically to http://erj.manuscriptcentral.com starting from now. We will allow for a 6-month-transition period where we will accept both electronic versions and hard copies. After that period we will only accept electronic manuscripts.

Besides these logistic improvements, we have also worked hard on the contents of the Journal, which after all is what matters most. The actions have been numerous, but concerted. The rejection rate is up to $70 \%$, as can be seen from figure 3 . This is primarily done to make the Journal more readable. It has led to a reduction in the number of printed pages from 3,001 in 1999 to 2,300 in 2000 . We plan to increase the rejection rate up to $75 \%$ in 2001 . We particularly reduced the number of case reports. We only consider these reports for publication provided they bring a substantially new message related to novel markers of disease, novel 


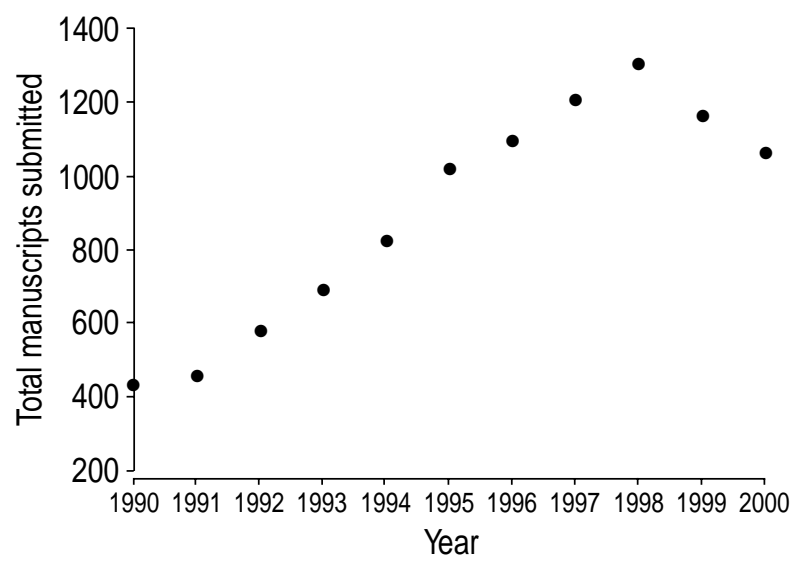

Fig. 1. - Number of manuscripts submitted to the European Respiratory Journal since 1990.

mechanisms, or novel treatments. The aim here is to publish one or at most two outstanding case reports per issue. The scientific impact of the Journal is not satisfactory as yet. In 1999 our impact factor increased to 2,334 . As can be seen from figure 4 our impact factor remained stable for the last 4 years after an important initial rise. We presently rank only eighth out of 30 publications in the respiratory field. We firmly believe that we can do better.

It is quite clear that the impact factor of a journal is important for several reasons. First, the impact factor of the publications of applicants are increasingly used by major granting institutions in order to decide on funding for scientific research. Second, authors are increasingly conscious of impact factors when deciding where to submit their work. Third, academic institutions across Europe are aware of impact factors and use them to make rankings for academic promotions. Nevertheless, the impact factor alone does not provide us with a complete assessment of the impact of a particular journal on scientific literature. This is rather determined by the total number of citations which is the product of the impact factor and the number of articles published. Table 1 gives an overview of the top 10 publications according to impact factor in 1999 and

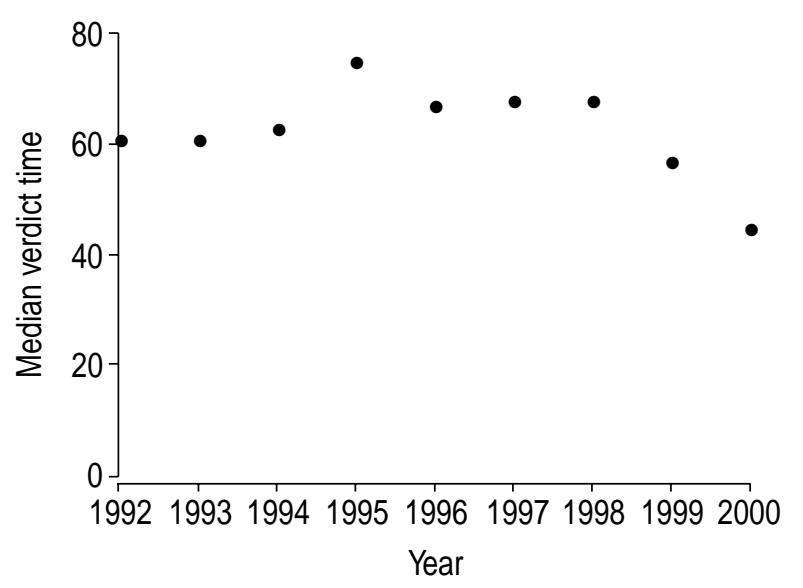

Fig. 2. - Median verdict time since 1992.

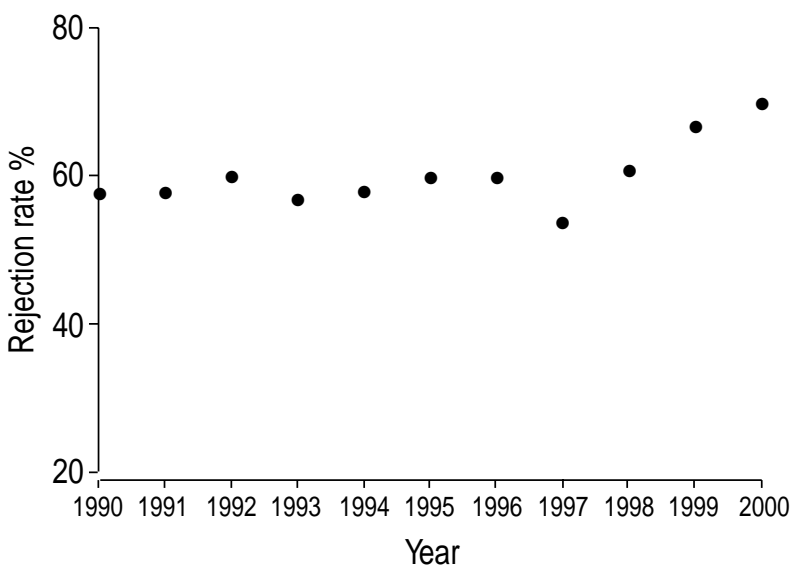

Fig. 3. - Rejection rate since 1990.

table 2 lists the top 10 publications according to total number of citations in the same year. As can be appreciated, the latter ranking is quite different from the ranking according to impact factor, indicating that the number of papers published is vastly different among journals.

In addition, we have worked hard in the year 2000 at attempting to improve our ranking. As stated above, we increased our impact factor slightly. We were highly proactive in trying to attract the best studies to the ERJ and we increased the proportion of high standard reviews. The assistant Chief Editors were quite active and helpful in attracting such reviews. Notwithstanding these changes, the ERJ will remain a journal primarily publishing original articles and will continue to provide a forum to publish some of the best original work in the field. We will also strengthen the synergy between the ERS and the Journal to carry over the momentum of the Society to the Journal. Several factors will help to strengthen these links. The ERS assemblies will be more involved in the selection of editorial board members, we will publish more guidelines and task force reports, and the excellent presentations at our annual meeting will form the basis of excellent original and review articles.

Finally, we also attempted to improve the standards



Fig. 4. - Impact factor of the European Respiratory Journal since 1992. 
Table 1.-Top ten journals according to impact factor in 1999

\begin{tabular}{lcc}
\hline Ranking & Journal & Impact factor \\
\hline 1. & Am J Respir Crit Care & 5.491 \\
2. & Am J Respir Cell Mol & 4.541 \\
3. & Thorax & 3.437 \\
4. & Am J Physiol-Lung C & 3.147 \\
5. & J Thorax Cardiov Sur & 2.986 \\
6. & J Heart Lung Transpl & 2.438 \\
7. & Chest & 2.410 \\
8. & Eur Respir J & 2.334 \\
9. & Clin Chest Med & 2.042 \\
10. & Ann Thorac Surg & 2.022 \\
\hline
\end{tabular}

and the content of the review process. We agreed on new uniform guidelines and newly developed definitions of the papers we are targeting. These guidelines are used by all Associate Editors, as an aid in the reviewing process. Along the way, we developed a new view on articles and their value to our Journal. Judging from the reviews of the articles of the last year, we believe that currently too much emphasis is being placed on methodology. Evidently and clearly, studies need to be carried out properly and the methods in the manuscript need to be
Table 2. - Top ten journals according to total number of citations in 1999

\begin{tabular}{lcc}
\hline Ranking & Journal & Total citations \\
\hline 1. & Chest & 21299 \\
2. & Am J Respir Crit Care & 18030 \\
3. & Ann Thorac Surg & 17209 \\
4. & J Thorac Cardiov Sur & 15342 \\
5. & Thorax & 8998 \\
6. & Eur Respir J & 7935 \\
7. & Am J Respir Cell Mol & 6565 \\
8. & Ann J Physiol-Lung C & 4205 \\
9. & J Heart Lung Transp & 2945 \\
10. & Int J Tuberc Lung D & 1628 \\
\hline
\end{tabular}

correctly applied, but methodology is not the only goal of a scientific publication. The most important part of a publication is the results, which consists of new original findings with a certain news value that convey a message to the reader and will either influence his scientific thinking or clinical practice substantially. We believe that reviewers often lose track of the basic message because of methodological concerns. In the year 2001, we would like to focus scientific publications towards their basic mission again. 